\title{
BMJ Open Associations of neonatal high birth weight with maternal pre-pregnancy body mass index and gestational weight gain: a case-control study in women from Chongqing, China
}

\author{
Yao Jie Xie, ${ }^{1,2}$ Rong Peng, ${ }^{1,3}$ Lingli Han, ${ }^{1}$ Xiaoli Zhou, ${ }^{4}$ Zhengai Xiong, ${ }^{5}$ \\ Yuan Zhang, ${ }^{6}$ Junnan Li, ${ }^{7}$ Ruoxue Yao, ${ }^{8}$ Tingyu Li, ${ }^{9}$ Yong Zhao ${ }^{1}$
}

To cite: Xie YJ, Peng R, Han L, et al. Associations of neonatal high birth weight with maternal pre-pregnancy body mass index and gestational weight gain: a case-control study in women from Chongqing, China. BMJ Open 2016;6:e010935. doi:10.1136/bmjopen-2015010935

- Prepublication history for this paper is available online. To view these files please visit the journal online (http://dx.doi.org/10.1136/ bmjopen-2015-010935).

YJX and RP contributed equally.

Received 28 December 2015 Revised 21 July 2016 Accepted 26 July 2016

\section{CrossMark}

For numbered affiliations see end of article.

Correspondence to Professor Yong Zhao; zhaoyongzb@qq.com and Professor Tingyu Li; tyli@vip.sina.com

\section{ABSTRACT}

Objectives: To examine the associations of maternal pre-pregnancy body mass index (BMI) and gestational weight gain (GWG) with neonatal high birth weight (HBW) in a sample of Chinese women living in southwest China.

Methods: A hospital-based case-control study was conducted in Chongqing, China. A total of 221 mothers who delivered HBW babies $(>4.0 \mathrm{~kg}$ ) were recruited as cases and 221 age-matched (2-year interval) mothers with normal birth weight babies $(2.5-4.0 \mathrm{~kg})$ were identified as controls. ORs were estimated using conditional logistic regression analysis. For the analysis, pre-pregnancy BMI was categorised as underweight/normal weight/overweight and obesity and GWG was categorised as inadequate/appropriate/ excessive.

Results: Among the cases, mean pre-pregnancy BMI was $21.8 \pm 2.8 \mathrm{~kg} / \mathrm{m}^{2}$, mean GWG was $19.7 \pm 5.1 \mathrm{~kg}$ and mean neonatal birth weight was $4.2 \pm 0.2 \mathrm{~kg}$. In the controls, the corresponding values were $21.1 \pm 3.1 \mathrm{~kg} /$ $\mathrm{m}^{2}, 16.4 \pm 5.0 \mathrm{~kg}$ and $3.3 \pm 0.4 \mathrm{~kg}$, respectively. More cases than controls gained excessive weight during pregnancy ( $80.1 \%$ vs $48.4 \%, p<0.001)$. No significant association was found between pre-pregnancy $\mathrm{BMI}$ and HBW babies (OR=1.04, 95\% $\mathrm{Cl} 0.97$ to $1.11 ; \mathrm{p}>0.05)$. GWG was positively related to HBW after adjustment for gravidity, gestational age, newborns' gender and family income $(O R=1.18,95 \% \mathrm{Cl} 1.12$ to 1.25 ; $\mathrm{p}<0.001)$. The adjusted OR of delivering HBW babies was $5.39(95 \% \mathrm{Cl} 2.94$ to $9.89 ; p<0.001)$ for excessive GWG versus appropriate GWG. This OR was strengthened among pre-pregnancy normal weight women $(\mathrm{OR}=10.27,95 \% \mathrm{Cl} 3.20$ to $32.95 ; \mathrm{p}<0.001)$.

Conclusions: Overall, the findings suggest a significantly positive association between GWG and HBW. However, pre-pregnancy BMI shows no independent relationship with HBW.

\section{BACKGROUND}

Birth weight has important correlations with later-life outcomes. $^{1-3}$ In the past 20 years,

\section{Strengths and limitations of this study}

- This research is the first hospital-based casecontrol study to examine the associations among pre-pregnancy body mass index (BMI), gestational weight gain and the risk of delivery of high birth weight (HBW) babies in a sample of Chinese women living in southwest China, where women have lower weight and lower gestational weight gain than women living in most other areas of China.

- Few lifestyle factors were collected in this study, thereby possibly limiting the adjustment of confounding factors. This deficiency might have introduced some bias.

- No gender-matched design (compared with controls, cases produced more male babies) and the absence of maternal nutrition data are other significant limitations of this study.

interest in the potential health risks associated with high birth weight (HBW, >4 kg) have increased. ${ }^{4}$ Many studies have shown that $\mathrm{HBW}$ is associated with several health problems in the perinatal period and in later life; these complications include dystocia and neonatal deaths, ${ }^{5}$ birth trauma and asphyxia, ${ }^{6}$ obesity, ${ }^{7}$ hypertension, ${ }^{8}$ diabetes mellitus ${ }^{9}{ }^{10}$ and cancer. ${ }^{11}$ The incidence of HBW babies has increased in recent years. ${ }^{12-14}$ Evidence has shown that several factors are linked to HBW, such as maternal smoking, drinking habits and pre-pregnancy care quality and policy. ${ }^{15-17}$ Among these factors, high pre-pregnancy body mass index (BMI) and excessive gestational weight gain (GWG) have been reported as two well-established risk factors for adverse pregnancy outcomes. $^{15}{ }^{18-23}$ A recent systematic review ${ }^{24}$ indicated that the risk of having an outcome related to $\mathrm{HBW}$ was almost triple among 
pre-pregnancy obese women in comparison with normal weight women ( $\mathrm{OR}=2.00,95 \%$ CI 1.84 to 2.18). A large sample study ${ }^{25}$ (with a total of 53541 single, live infants delivered) conducted in white, black and Hispanic women in western countries found that the risk for HBW increased with increasing GWG in all prepregnancy BMI categories, and the magnitude of risk varied according to BMI status. ${ }^{25}$ Thus, further insights into the joint effect of pre-pregnancy BMI and GWG on neonatal birth weight should be explored.

Women in developing countries have a lower weight and less GWG than those in developed countries. ${ }^{26} 27$ Typically, in remote areas of China, such as Chongqing, a southwestern city nearby the $\mathrm{Si}$ Chuan province, women have a lower weight and lower $\mathrm{GWG}^{15}$ than those from most other areas of China. We wondered how women's pre-pregnancy BMI and GWG status affected neonatal birth weight in this area and whether it differed from results of previous studies conducted in other populations and countries? To date, no comparable studies have focused on this population. Therefore, we investigated the associations of pre-pregnancy BMI and GWG with neonatal HBW and estimated the strength of association among different pre-pregnancy BMI and GWG groups in the women living in Chongqing, China.

\section{METHODS}

\section{Study setting and participants}

This hospital-based case-control study was conducted from March 2010 to March 2012 at four hospitals in Chongqing. Local women with singleton term pregnancies and live infants delivered qualified as potential participants for this study. The sample size calculation was based on the probability of exposure (pre-pregnancy BMI: overweight and obesity was $13.88 \%)^{28}$ among sampled control subjects and the correlation coefficient for exposure between matched cases and controls (0.2). A sample of 199 case subjects was needed. With a matching ratio of 1:1 for control subjects, the total sample of 398 subjects can achieve $80 \%$ power to detect an OR of 2.50 versus the alternative of equal odds using a $\chi^{2}$ test with 0.05 significance level.

Inclusion criteria for the cases were (1) women with 37-42-week gestation period living births (singleton term pregnancies and live infants delivered); (2) newborn with a HBW of $>4.0 \mathrm{~kg}$ ) $;{ }^{29}$ (3) no congenital diseases, gastrointestinal malformations or cardiovascular diseases; (4) household long-term residents of Chongqing and (5) mothers with uncomplicated, singleton pregnancies. Exclusion criteria were (1) gestational age of $>42$ or $<37$ weeks; (2) placenta previa or preeclampsia; (3) mothers with gestational diabetes or medical disorders, such as diabetes mellitus, chronic hypertension, cardiac or endocrine disorders and surgical conditions; (4) birth deficiencies, gastrointestinal disease deformity, cardiovascular diseases and neonatal hypoxic-ischaemic encephalopathy (severe); (6) having necrotising enterocolitis and other neurological and gastrointestinal diseases after birth; (7) non-long-term residents of Chongqing household registration $(<3$ years) and (8) hospitalisation of $>30$ days. Hospitalised pregnant women who met the above inclusion and exclusion criteria were recruited as cases. One age-matched ( \pm 2 years) hospital-based control subject, selected from the same hospitals, was recruited for each case. The same inclusion and exclusion criteria were applied to the control subjects, except for the delivery of HBW babies; control subjects had to have a delivery of normal birth weight babies of $2.5-4.0 \mathrm{~kg}) .^{29}$

A total of 221 cases and 221 controls were recruited. Written informed consent was obtained from each participant. The study protocol was reviewed and approved by the institutional ethics committee of Chongqing Medical University, China.

\section{Measures}

Mothers' ages (identified from the identity card), height, pre-pregnancy body weight, body weight at delivery and reproductive characteristics (gravidity, parity, mode of delivery, prenatal genetic diseases, pregnancy duration, frequency of prenatal examination, blood pressure and pregnancy complications), as well as newborns' information, including birth weight, birth length, gender and gestational age, were all extracted from the participants' hospital medical records. These variables were objectively measured by professional healthcare staff. A face-to-face interview was also conducted by trained medical staff and graduate students from the Chongqing Medical University to obtain parents' demographic data and other information, including mothers' and fathers' education level, occupation, monthly income, as well as fathers' age, height and weight.

Gestational age was calculated from the first day of the last menstrual period or taken from the dating ultrasound scan performed before 20 weeks of pregnancy. Pre-pregnancy BMI was calculated as pre-pregnancy weight $(\mathrm{kg})$ divided by squared height $\left(\mathrm{m}^{2}\right)$. GWG was calculated from the maternal body weight at delivery and pre-pregnancy body weight as recorded on the hospital medical records. According to the Chinese maternal prepregnancy BMI status ${ }^{30}$ pre-pregnancy BMI was categorised as underweight $\left(<18.5 \mathrm{~kg} / \mathrm{m}^{2}\right)$, normal weight $(18.5$ $\left.23.9 \mathrm{~kg} / \mathrm{m}^{2}\right)$, overweight $\left(24.0-27.9 \mathrm{~kg} / \mathrm{m}^{2}\right)$, or obese $\left(\geq 28 \mathrm{~kg} / \mathrm{m}^{2}\right)$. In accordance with the 2009 IOM GWG recommendations, ${ }^{31}$ GWG was defined as one of three types: inadequate, appropriate and excessive. Inadequate GWG was considered as gaining weight of $<12.5 \mathrm{~kg}$ for underweight mothers, $<11.5 \mathrm{~kg}$ for normal weight, $<7.0 \mathrm{~kg}$ for overweight and $<5.0 \mathrm{~kg}$ for obese mothers. Appropriate GWG was considered as gaining weight of $12.5-18.0 \mathrm{~kg}$ for underweight, $11.5-16.0 \mathrm{~kg}$ for normal weight, 7.0 $11.5 \mathrm{~kg}$ for overweight and $5.0-9.0 \mathrm{~kg}$ for obese mothers. Excessive GWG was defined as gaining weight of $>18.0 \mathrm{~kg}$ for underweight, $>16.0 \mathrm{~kg}$ for normal weight, $>11.5 \mathrm{~kg}$ for overweight and $>9.0 \mathrm{~kg}$ for obese mothers. ${ }^{31}$ 


\section{Statistical analyses}

Descriptive characteristics of variables were expressed as means and frequencies. Student's $t$ test was used to examine the differences of means for continuous variables and Pearson's $\chi^{2}$ test was performed to compare the categorical variables between cases and controls. Conditional logistic regression models were used to calculate ORs and 95\% CIs for being HBW by one unit increase in pre-pregnancy BMI $\left(\mathrm{kg} / \mathrm{m}^{2}\right)$ and GWG $(\mathrm{kg})$, respectively; the ORs and CIs of each pre-pregnancy BMI category (underweight/normal weight/overweight and obesity) and each GWG category (inadequate/ appropriate/excessive) were also calculated, with the normal weight category and appropriate GWG category serving as references after adjusting for the potential confounding variables. Interaction terms of prepregnancy BMI and GWG were constructed and tested in the multivariate model. Linear trends across increasing categories were tested by assigning categories as continuous variables in the regression. To determine whether the effect of GWG on birth weight was modified by pre-pregnancy BMI, we conducted stratified analysis by separating the participants into underweight, normal weight, overweight and obesity categories according to their pre-pregnancy BMI status. All statistical analyses were performed with SPSS V.22.1 for Windows (SPSS Inc, Chicago, Illinois, USA). All reported probabilities ( $p$ values) were two sided, with $\mathrm{p}<0.05$ considered statistically significant.

\section{RESULTS}

A total of 235 eligible cases and 232 matched controls were recruited from four hospitals in Chongqing. During the interview period, 14 cases and 11 controls left the study. Finally, 221 cases and 221 controls were involved in the analysis. Among the cases, the mean neonatal birth weight was $4.2 \pm 0.2 \mathrm{~kg}$, the mean prepregnancy BMI was $21.8 \pm 2.8 \mathrm{~kg} / \mathrm{m}^{2}$ and the mean GWG was $19.7 \pm 5.1 \mathrm{~kg}$. In the controls, the mean neonatal birth weight was $3.3 \pm 0.4 \mathrm{~kg}$ and the mean pre-pregnancy BMI and GWG were $21.1 \pm 3.1 \mathrm{~kg} / \mathrm{m}^{2}$ and $16.4 \pm 5.0 \mathrm{~kg}$, respectively. Other basic characteristics of the participants are listed in table 1. Up to $45 \%(199 / 442)$ of participants' gestational age was determined by the dating ultrasound scan. This proportion was similar in cases and controls $(44.3 \%$ vs $45.7 \%, \mathrm{p}>0.05)$. Significant differences were seen in the gravidity, gestational age, gender of newborn, GWG and family income between the cases and controls (all $\mathrm{p}<0.05)$. No significant differences were found in the pre-pregnancy BMI, parity, father's age, father's BMI, maternal age, maternal education level, maternal work and family history of diabetes (all $\mathrm{p}>0.05$ ).

Table 2 shows the mean GWG on the basis of different categories of pre-pregnancy BMI in the cases and controls. On average, cases had a $3.4 \mathrm{~kg}$ and $3.7 \mathrm{~kg}$ higher GWG than controls in the pre-pregnancy underweight and normal weight categories, respectively (both $\mathrm{p}<0.01)$. No significant difference in GWG was found between cases and controls in the pre-pregnancy overweight/obese category $(p>0.05)$. Table 3 and figure 1 further show the number of cases and controls in different GWG categories. Figure 1 also illustrates the distribution of pre-pregnancy BMI status in each GWG category. Among the cases, $80.1 \%(177 / 221)$ of subjects had excessive weight gain during pregnancy, in comparison with $48.4 \%(107 / 221)$ in the controls. The $\chi^{2}$ test showed a significant difference between the cases and controls (table 3) $(p<0.001)$. The result indicated that the cases were more likely to gain excessive weight than the controls during pregnancy. However, the cases and controls showed no significantly different distributions according to their pre-pregnancy BMI categories $(\mathrm{p}>0.05)$.

The ORs of being HBW by one unit increase in prepregnancy BMI and GWG are presented in table 4 . The crude odds was $16 \%$ greater with each kilogram of GWG $(\mathrm{OR}=1.16,95 \%$ CI 1.10 to $1.21 ; \mathrm{p}<0.001)$. Given that the gravidity, gestational age and gender of the newborns were significantly different between the cases and controls, these variables were adjusted in the model as confounders. After adjusting for these factors, the OR for GWG increased slightly to 1.18 (95\% CI 1.12 to 1.25 ) and remained stable when further adjusted for prepregnancy BMI (combined model). No significant association between pre-pregnancy BMI and HBW was found, with or without adjustment for the covariates (all $\mathrm{p}>0.05$ ). No significant interaction existed between prepregnancy BMI and GWG on neonatal birth weight $(p>0.05)$. In the stratified models by pre-pregnancy BMI status, a strengthened association between GWG and HBW was found among pre-pregnancy normal weight women $(\mathrm{OR}=1.20,95 \%$ CI 1.10 to $1.31 ; \mathrm{p}<0.001)$. However, the associations were not statistically significant among pre-pregnancy underweight and overweight/ obese women (both $\mathrm{p}>0.05$ ).

Table 5 shows the ORs of being HBW for different categories of pre-pregnancy BMI and GWG, as well as for GWG subgroups among pre-pregnancy normal weight mothers. Compared with mothers who had normal weight before pregnancy, those who were underweight before pregnancy seemed less likely to produce HBW babies (adjusted $\mathrm{OR}=0.86,95 \%$ CI 0.43 to 1.72 ), but the association was not statistically significant $(p>0.05)$. Furthermore, no significant association was found between overweight/obesity and HBW (adjusted $\mathrm{OR}=1.16,95 \%$ CI 0.63 to $2.14 ; \mathrm{p}=0.634$ ). For the $\mathrm{GWG}$ categories, HBW was positively associated with the increased hierarchy of GWG ( $p$ trend $<0.001$ in both models with and without adjustment). Compared with the appropriate GWG, the adjusted OR of being HBW for the excessive GWG was 5.39 (95\% CI 2.94 to 9.89; $\mathrm{p}<0.001)$. When we stratified the participants for subgroup analysis according to their pre-pregnancy BMI status, we found that the association of excessive GWG 
Table 1 Characteristics of the participants

\section{Characteristics}

Maternal age (years)

Maternal pre-pregnancy BMI $\left(\mathrm{kg} / \mathrm{m}^{2}\right)$

Gestational weight gain $(\mathrm{kg})$

Gestational age (weeks)

Neonatal birth weight $(\mathrm{kg})$

Gender of newborn, n (\%)

Boy

Girl

Gravidity, n (\%)

1

$\geq 2$

Parity, n (\%)

$\geq 2$

Completed maternal education, $\mathrm{n}(\%)$

$\leq 9$ years

$\geq 10-15$ years

$\geq 16$ years

Maternal work, $\mathrm{n}(\%)$

Civil servant

Self-employed

Agricultural workers

Unemployed

Clerk

Father's age (years)

Father's BMI $\left(\mathrm{kg} / \mathrm{m}^{2}\right)$

Family income (RMB/month), n (\%)

$<800$

800-1999

2000-4999

$\geq 5000 \mathrm{RMB} /$ month

Family history of diabetes, $\mathrm{n}(\%)$

Yes

No
Cases: mothers with HBW infants

( $\mathrm{N}=221)$

$28.7 \pm 4.2$

$21.8 \pm 2.8$

$19.7 \pm 5.2$

$39.4 \pm 1.0$

$4.2 \pm 0.2$

$144(65.2)$

77 (34.8)

$155(70.1)$

66 (29.9)

$216(97.7)$

5 (2.3)

$20(9.0)$

$106(48.0)$

95 (43.0)

45 (20.4)

89 (40.3)

5 (2.3)

$19(8.6)$

63 (28.5)

$31.6 \pm 4.8$

$24.1 \pm 3.2$

5 (2.3)

$22(10.0)$

$111(50.2)$

83 (37.6)

50 (22.6)

$171(77.4)$
Controls: mothers

with NBW infants

( $\mathrm{N}=221)$

p Value

$28.9 \pm 4.2$

0.593

$21.3 \pm 3.4$

0.128

$16.4 \pm 5.0$

$38.6 \pm 1.1$

$3.3 \pm 0.5$

$<0.001$

$<0.001$

$<0.001$

0.026

$121(54.8)$

$100(45.2)$

$188(85.1)$

33 (14.9)

$216(97.7)$

5 (2.3)

18 (8.2)

$111(50.2)$

92 (41.6)

$<0.001$

1.000

0.887

30 (13.6)

80 (36.1)

7 (3.2)

22 (10.0)

82 (37.1)

$32.1 \pm 5.0$

0.273

$23.9 \pm 3.3$

0.636

7 (3.2)

$17(7.7)$

156 (70.6)

41 (18.6)

0.163

$<0.001$

49 (22.2)

$172(77.8)$

Table 2 Gestational weight gain according to maternal pre-pregnant body mass index (BMI) categories in cases and controls

\begin{tabular}{|c|c|c|c|c|c|c|}
\hline \multirow[b]{2}{*}{ Groups } & \multicolumn{2}{|c|}{$\begin{array}{l}\text { Underweight } \\
\mathrm{BMI}<18.5\end{array}$} & \multicolumn{2}{|c|}{$\begin{array}{l}\text { Normal weight } \\
18.5 \leq \mathrm{BMI}<23.9\end{array}$} & \multicolumn{2}{|c|}{$\begin{array}{l}\text { Overweight \& } \\
\text { obesity } \\
\text { BMI } \geq 24\end{array}$} \\
\hline & $\bar{n}$ & GWG (kg) & $\mathrm{n}$ & GWG (kg) & $\bar{n}$ & GWG (kg) \\
\hline Cases: mothers with HBW infants & 27 & $19.9 \pm 5.5$ & 158 & $20.1 \pm 4.8$ & 36 & $18.0 \pm 6.3$ \\
\hline Controls: mothers with NBW infants & 39 & $16.5 \pm 3.8$ & 149 & $16.4 \pm 4.9$ & 33 & $15.8 \pm 6.5$ \\
\hline $\mathrm{p}$ Value & & 0.004 & & $<0.001$ & & 0.161 \\
\hline
\end{tabular}

with HBW was strengthened among pre-pregnancy normal weight mothers; the adjusted odds was 10.3 times greater than that for appropriate GWG mothers (adjusted $\mathrm{OR}=10.27 ; \mathrm{p}<0.001$ ) with a wide $\mathrm{CI}$ of 3.20 to 32.95. Given the limited number of underweight, overweight and obese participants in the cases and controls
(27-39), the sample size was too small for further stratified analysis to calculate OR by three GWG subgroups among these two pre-pregnancy BMI categories (eg, the inadequate GWG subgroup among underweight category had only three cases and five controls). Therefore, the corresponding data are not shown. 
Table 3 Number and proportion of cases and controls according to maternal pre-pregnancy body mass index (BMI) categories and gestational weight gain groups

\begin{tabular}{|c|c|c|c|c|c|}
\hline & \multicolumn{2}{|c|}{$\begin{array}{l}\text { Cases: mothers } \\
\text { with HBW infants }\end{array}$} & \multicolumn{2}{|c|}{$\begin{array}{l}\text { Controls: mothers } \\
\text { with NBW infants }\end{array}$} & \multirow[b]{2}{*}{ p Value } \\
\hline & $\overline{\mathbf{n}}$ & $\%$ & $\bar{n}$ & $\%$ & \\
\hline Maternal pre-pregnancy BMI categories & & & & & 0.276 \\
\hline Underweight & 27 & 12.2 & 39 & 17.6 & \\
\hline Normal weight & 158 & 71.5 & 149 & 67.4 & \\
\hline Overweight or obesity & 36 & 16.3 & 33 & 14.9 & \\
\hline Gestational weight gain groups & & & & & $<0.001$ \\
\hline Inadequate & 9 & 4.1 & 26 & 11.8 & \\
\hline Appropriate & 35 & 15.8 & 88 & 39.8 & \\
\hline Excessive & 177 & 80.1 & 107 & 48.4 & \\
\hline
\end{tabular}

Figure 1 Number of cases and controls in different gestational weight gain groups. Distribution of maternal pre-pregnancy BMI status in each gestational weight gain group. BMl, body mass index; HBW, high birth weight; NBW, normal birth weight.
Controls (mother with NBW infant) and Cases (mother with HBW infant)

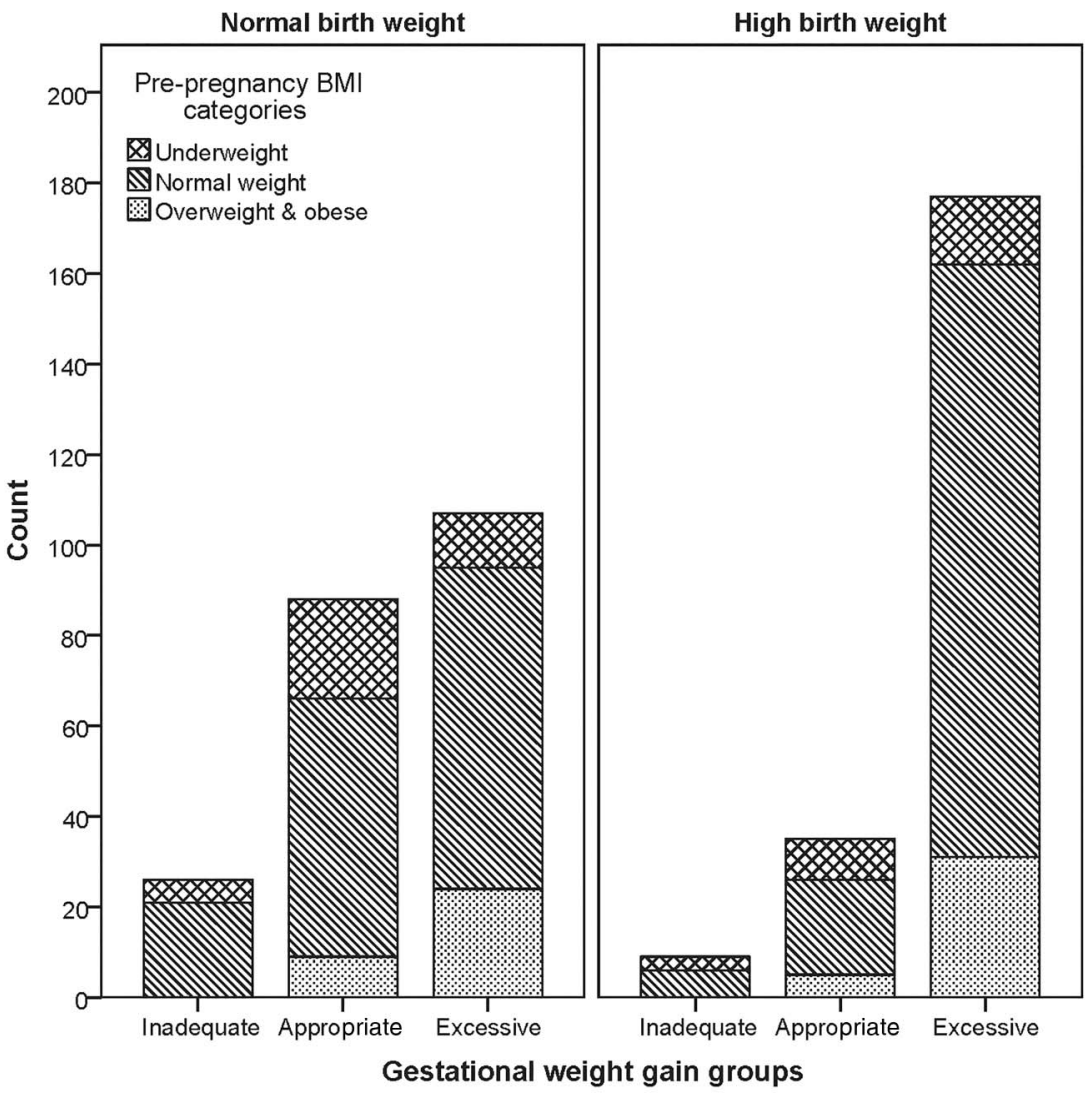

Gestational weight gain groups

\section{DISCUSSION}

We examined the associations between pre-pregnancy BMI, weight gain during pregnancy and delivery of HBW babies in a sample of Chinese women living in southwest China. We found a positive relationship between GWG and HBW, in which a higher weight gain during pregnancy predicted a higher probability of delivering HBW babies. Excessive GWG was the most significant factor associated with the delivery of HBW babies in this study. We found no significant association between pre-pregnancy BMI and HBW, but we found that the effect of GWG on birth weight was modified by pre-pregnancy BMI status. The strongest GWG-HBW association existed in the pre-pregnancy normal weight women who gained excessive weight during pregnancy.

Maternal nutrition is critical for fetal growth and development. In our study, the average GWG was $14.2 \mathrm{~kg}$ among normal weight women with normal birth weight babies; our finding was lower than found in a recent publication, which indicated an average weight gain of $16.2 \mathrm{~kg}$ in the same BMI category of women who lived in Beijing. ${ }^{32}$ Chongqing is a southwestern city in China and Beijing is the capital. The above finding is consistent with a previous study, ${ }^{15}$ indicating that women who live 
Table 4 ORs of being HBW per unit increase in pre-pregnancy BMI and gestational weight gain $(\mathrm{kg})$ by conditional logistic regression analysis

\begin{tabular}{|c|c|c|c|}
\hline & OR & $95 \% \mathrm{Cl}$ & p Value \\
\hline \multicolumn{4}{|l|}{ Simple model ${ }^{*}$} \\
\hline Pre-pregnancy BMI & 1.05 & 0.99 to 1.12 & 0.124 \\
\hline GWG & 1.16 & 1.10 to 1.21 & $<0.001$ \\
\hline \multicolumn{4}{|l|}{ Adjusted model† } \\
\hline Pre-pregnancy BMI & 1.04 & 0.97 to 1.11 & 0.320 \\
\hline GWG & 1.18 & 1.12 to 1.25 & $<0.001$ \\
\hline \multicolumn{4}{|l|}{ Combined model } \\
\hline Pre-pregnancy BMI & 1.04 & 0.96 to 1.13 & 0.313 \\
\hline GWG & 1.18 & 1.12 to 1.25 & $<0.001$ \\
\hline Interaction term: pre-pregnancy BMI × GWG§ & 0.99 & 0.98 to 1.01 & 0.374 \\
\hline \multicolumn{4}{|l|}{ Stratified model } \\
\hline GWG among pre-pregnancy underweight women & 0.34 & 0.05 to 2.19 & 0.255 \\
\hline GWG among pre-pregnancy normal weight women & 1.20 & 1.10 to 1.31 & $<0.001$ \\
\hline GWG among pre-pregnancy overweight/obese women & 1.08 & 0.99 to 1.17 & 0.089 \\
\hline \multicolumn{4}{|c|}{$\begin{array}{l}\text { *Crude OR was calculated for pre-pregnancy BMI and GWG (continuous variable, } \mathrm{kg} \text { ). } \\
\text { †Adjusted OR was calculated for pre-pregnancy BMI and GWG (continuous variable, } \mathrm{kg} \text { ). Gestational age, gender of newborn, gravidity and } \\
\text { family income were adjusted as covariates. } \\
\text { †Combined model was constructed to calculate the adjusted ORs by putting pre-pregnancy BMI and GWG (both as continuous variables) into } \\
\text { one model. Gestational age, gender of newborn, gravidity and family income were adjusted as covariates. The interaction between } \\
\text { pre-pregnancy BMI and GWG was examined. } \\
\text { १The association between GWG and HBW was analysed according to different pre-pregnancy BMI statuses. } \\
\text { §The interaction term = pre-pregnancy BMI } \times \text { GWG. } \\
\text { BMI, body mass index; GWG, gestational weight gain; HBW, high birth weight. }\end{array}$} \\
\hline
\end{tabular}

Table 5 Association of HBW with categories of maternal pre-pregnancy body mass index (BMI) and gestational weight gain; Chongqing, China, 2012

\begin{tabular}{|c|c|c|c|c|c|c|c|c|}
\hline & \multicolumn{2}{|c|}{$\begin{array}{l}\text { Cases: mothers } \\
\text { with HBW } \\
\text { infants }(n=221)\end{array}$} & \multicolumn{2}{|c|}{$\begin{array}{l}\text { Controls: } \\
\text { mothers with } \\
\text { NBW infants } \\
(n-=221)\end{array}$} & \multicolumn{2}{|l|}{ Unadjusted } & \multicolumn{2}{|l|}{ Adjusted $^{*}$} \\
\hline & $\overline{\text { Mean } \pm \text { SD † }}$ & $\mathbf{n}$ & $\overline{M e a n} \pm$ SD $†$ & $\mathbf{n}$ & OR (95\% Cl) & p Value & OR (95\% Cl) & p Value \\
\hline \multicolumn{9}{|c|}{ Maternal pre-pregnancy BMI categories } \\
\hline Normal weight & $21.4 \pm 1.4$ & 158 & $20.9 \pm 1.4$ & 149 & 1.00 & & 1.00 & \\
\hline Underweight & $17.7 \pm 0.8$ & 27 & $17.6 \pm 0.6$ & 39 & $0.70(0.39$ to 1.27$)$ & 0.241 & $0.86(0.43$ to 1.72$)$ & 0.669 \\
\hline Overweight and obese & $26.5 \pm 2.1$ & 36 & $27.5 \pm 3.8$ & 33 & $1.04(0.62$ to 1.74$)$ & 0.895 & $1.16(0.63$ to 2.14$)$ & 0.634 \\
\hline $\mathrm{p}$ Trend $\ddagger$ & & & & & & 0.198 & & 0.364 \\
\hline \multicolumn{9}{|l|}{ GWG categories } \\
\hline Appropriate & $14.4 \pm 2.7$ & 35 & $14.0 \pm 2.2$ & 88 & 1.00 & & 1.00 & \\
\hline Inadequate & $9.3 \pm 1.4$ & 9 & $9.8 \pm 1.3$ & 26 & $0.33(0.04$ to 3.21$)$ & 0.341 & $0.19(0.01$ to 3.30$)$ & 0.253 \\
\hline Excessive & $21.3 \pm 4.3$ & 177 & $19.9 \pm 4.4$ & 107 & 3.75 (2.29 to 6.14$)$ & $<0.001$ & 5.39 (2.94 to 9.89$)$ & $<0.001$ \\
\hline p Trend $\ddagger$ & & & & & & $<0.001$ & & $<0.001$ \\
\hline \multicolumn{9}{|c|}{ GWG among pre-pregnancy normal weight women } \\
\hline Appropriate & $14.5 \pm 1.4$ & 21 & $14.2 \pm 1.2$ & 57 & 1.00 & & 1.00 & \\
\hline Inadequate & $8.9 \pm 1.3$ & 6 & $9.6 \pm 1.3$ & 21 & - & - & - & - \\
\hline Excessive & $21.5 \pm 3.8$ & 131 & $20.3 \pm 4.0$ & 71 & 5.50 (2.31 to 13.13$)$ & $<0.001$ & 10.27 (3.20 to 32.95$)$ & $<0.001$ \\
\hline
\end{tabular}

in remote areas of China have a relatively lower GWG, which reflects the discrepancy of living conditions and nutrition status in different areas of China. In our study, the weight gain of the cases during pregnancy was higher than that of the controls in pre-pregnancy overweight and obese women (18.0 kg vs $15.8 \mathrm{~kg})$. However, the difference was not statistically significant. We suggest that the small sample size in this group might have led 
to insufficient power to detect the difference. Nevertheless, GWG was higher in cases than in controls in both underweight and normal weight groups, indicating that the mothers with neonatal HBW were more likely to gain more weight during pregnancy, whether or not they were underweight or had normal weight before pregnancy.

We found no significant positive association between pre-pregnancy BMI and birth weight. This finding was in contrast to most previous studies, ${ }^{15} 19222333-36$ probably because our study was conducted in a remote area of China, with a different population and different access to healthcare and resources. When we analysed the association by grouping the BMI into three categories, no significant association was found between pre-pregnancy overweight/obesity and HBW, or between pre-pregnancy underweight and HBW. GWG had a more important role in the delivery of HBW babies. Findings from logistic regression analysis indicated that GWG had significant effect on neonatal birth weight, as higher GWG was associated with a higher risk of HBW. This finding is consistent with many previous studies. ${ }^{15}$ 37-39 However, when we examined the effect of modification of prepregnancy BMI on the GWG-HBW association, we obtained a statistically significant association only among pre-pregnancy normal weight participants. The limited sample size in the other two BMI subgroups (underweight and overweight/obese) might have led to insufficient power to detect the effect. Nevertheless, the significant association between GWG and HBW across all prepregnancy BMI ranges suggests that a reasonable weight gain is important during pregnancy, whether the women are thin, obese or of normal weight during the prepregnancy period. Thus, women should gain appropriate weight during pregnancy according to their BMI status. ${ }^{40}$ In our study, pre-pregnancy normal weight women with excessive GWG had high odds of having HBW babies, suggesting that average-sized women should pay more attention to their diets and lifestyle during pregnancy.

The mechanism of maternal pre-pregnancy and prenatal anthropometric parameters affecting neonatal birth weight is unclear. Possible explanations include hormone levels, such as obesity-related insulin resistance and genetic factors, both of which have been shown to be associated with abnormal birth. The co-presence of undetected disease during pregnancy, such as type 2 or gestational diabetes, is another possible cause. Efforts should be devoted to the management of maternal anthropometric parameters during pre-pregnancy and the prenatal period to achieve normal BMI before pregnancy and keep the weight gain in an appropriate range during pregnancy.

The worldwide epidemic of adolescent and adult chronic diseases might be a result of our lifestyle of inadequate activity and poor diet but might also be induced at a much earlier stage in life. ${ }^{41}$ As it is relatively difficult to achieve long-term lifestyle changes for the treatment of chronic disease, preventing diseases at an early stage of life is important. The potential for intrauterine treatment and prevention of abnormal fetal weight, possibly through lifestyle measures before and during gestation, should become a focus of research for short- and long-term prevention of adult chronic diseases. Consequently, previous studies have highly recommended prenatal care before pregnancy. ${ }^{42}$ Prevention rather than treatment may be the best choice to eliminate the vicious cycle of adult chronic metabolic diseases before and during pregnancy.

In our study, the absence of a gender-matched design (compared with controls, cases had more male babies) is a limitation in the selection of a comparable control group. Despite any common limitations inherent in the case-control study, our study also has some particular limitations. First, given the small sample of pre-pregnancy overweight and obese participants, we were unable calculate the OR for each GWG subgroup. Second, we used two methods to calculate gestational age, which might have led to some measurement bias. However, we suggest that the influence of this on the main results was negligible because comprehensive adjustment (including adjustment for gestational age) was made in subsequent regression analysis. Nevertheless, consistent methods of measuring gestational age are suggested for future studies. Third, maternal nutrition data were not considered in this study. Maternal nutrition is strongly associated with prepregnancy BMI and GWG and detailed information might have further elucidated the results. In addition, details of some potentially confounding factors, such as smoking and alcohol consumption during pregnancy, were not collected in the study. Nevertheless, we suggest that this deficiency would not overturn the findings.

In summary, our study showed a significantly positive association between GWG and HBW. However, there was no independent relationship between pre-pregnancy BMI and HBW. Individualised pre-pregnancy care and prenatal care for women with different BMI and GWG statuses is warranted. The study can be developed further by designing interventions to control the appropriate weight gain during pregnancy in this population.

\section{Author affiliations}

${ }^{1}$ College of Public Health and Management, Chongqing Medical University, Chongqing, China

${ }^{2}$ School of Nursing, The Hong Kong Polytechnic University, Hong Kong, Hong Kong

${ }^{3}$ Affiliated Hospital of Chengdu University, Chengdu, China

${ }^{4}$ The First Affiliated Hospital of Chongqing Medical University, Chongqing,

China

${ }^{5}$ The Second Affiliated Hospital of Chongqing Medical University, Chongqing, China

${ }^{6}$ Chongqing Maternal and Child Health Care Hospital, Chongqing, China

${ }^{7}$ The First Affiliated Hospital of the Third Military Medical University, Chongqing, China

${ }^{8}$ Department of Nutritional Sciences, University of Cincinnati, Cincinnati, USA ${ }^{9}$ Children's Nutrition Research Centre, Key Laboratory of Developmental Diseases in Childhood of Education Ministry, Children's Hospital of Chongqing Medical University, Chongqing, China

Acknowledgements We thank Haili Xue, Yaling Qie, Lingli Han, Xiaoyang Xu, Yong Zhang, Zhanzhan Zhang, Yiyin Xia, Ting Yang, Li Zhou, Huan Zeng, Qin 
Liu, Ling Zhang, Xuewei Yang and Jingqiu Wang for their data collection in the hospitals. We also acknowledge the support from all team members, study participants and local hospital staff.

Contributors YoZ, YJX, RP and RY designed and carried out the study, performed the statistical analysis and drafted the manuscript; TL, YZ, XZ, ZX, YuZ, LH and JL contributed to the study design and data collection. All authors read and approved the final manuscript.

Funding This study was supported by grants from the National Natural Science Foundation of China (NSFC) (grant number 30901189).

Competing interests None declared.

Patient consent Obtained.

Ethics approval Institutional ethics committee of Chongqing Medical University.

Provenance and peer review Not commissioned; externally peer reviewed.

Data sharing statement No additional data are available.

Open Access This is an Open Access article distributed in accordance with the Creative Commons Attribution Non Commercial (CC BY-NC 4.0) license, which permits others to distribute, remix, adapt, build upon this work noncommercially, and license their derivative works on different terms, provided the original work is properly cited and the use is non-commercial. See: http:// creativecommons.org/licenses/by-nc/4.0/

\section{REFERENCES}

1. Bukowski R, Uchida T, Smith GC, et al. Individualized norms of optimal fetal growth: fetal growth potential. Obstet Gynecol 2008;111:1065-76.

2. Eriksson JG. The fetal origins hypothesis-10 years on. BMJ 2005;330:1096-7.

3. Gluckman PD, Hanson MA, Cooper C, et al. Effect of in utero and early-life conditions on adult health and disease. $N$ Engl $J$ Med 2008;359:61-73.

4. Eriksen W. Invited commentary: interpreting associations between high birth weight and later health problems. Am J Epidemiol 2014:180:885-7.

5. Rossi AC, Mullin P, Prefumo F. Prevention, management and outcomes of macrosomia: a systematic review of literature and meta-analysis. Obstet Gynecol Surv 2013;68:702-9.

6. Bjorstad AR, Irgens-Hansen K, Daltveit AK, et al. Macrosomia: mode of delivery and pregnancy outcome. Acta Obstet Gynecol Scand 2010;89:664-9.

7. Schellong K, Schulz S, Harder T, et al. Birth weight and long-term overweight risk: systematic review and a meta-analysis including 643,902 persons from 66 studies and 26 countries globally. PloS ONE 2012;7:e47776.

8. Zhang Y, Li H, Liu SJ, et al. The associations of high birth weight with blood pressure and hypertension in later life: a systematic review and meta-analysis. Hypertens Res 2013;36:725-35.

9. Harder T, Roepke K, Diller N, et al. Birth weight, early weight gain and subsequent risk of type 1 diabetes: systematic review and meta-analysis. Am J Epidemiol 2009;169:1428-36.

10. Harder T, Rodekamp E, Schellong K, et al. Birth weight and subsequent risk of type 2 diabetes: a meta-analysis. Am J Epidemiol 2007;165:849-57.

11. Ahlgren M, Wohlfahrt J, Olsen LW, et al. Birth weight and risk of cancer. Cancer 2007;110:412-19.

12. Lahmann PH, Wills RA, Coory M. Trends in birth size and macrosomia in Queensland, Australia, from 1988 to 2005. Paediatr Perinat Epidemiol 2009;23:533-41.

13. Donahue SM, Kleinman KP, Gillman MW, et al. Trends in birth weight and gestational length among singleton term births in the United States 1990-2005. Obstet Gynecol 2010;115:357-64.

14. Martin JA, Hamilton BE, Sutton PD, et al. Births: final data for 2007. Natl Vital Stat Rep 2010;58:1-85.

15. Liu Y, Dai W, Dai X, et al. Prepregnancy body mass index and gestational weight gain with the outcome of pregnancy: a 13-year study of 292,568 cases in China. Arch Gynecol Obstet 2012;286:905-11.

16. Villar J, Bergsjo P. Scientific basis for the content of routine antenatal care. I. Philosophy, recent studies and power to eliminate or alleviate adverse maternal outcomes. Acta Obstet Gynecol Scand 1997;76:1-14.
17. Hirnle L, Kowalska M, Petrus A, et al. [The analysis of risk factors for fetal macrosomia and the complications in the course of pregnancy and delivery of macrosomic baby]. Ginekologia polska 2007;78:280-3.

18. Jensen DM, Damm P, Sorensen B, et al. Pregnancy outcome and prepregnancy body mass index in 2459 glucose-tolerant Danish women. Am J Obstet Gynecol 2003;189:239-44.

19. Frederick IO, Williams MA, Sales AE, et al. Pre-pregnancy body mass index, gestational weight gain and other maternal characteristics in relation to infant birth weight. Matern Child Health $J$ 2008;12:557-67.

20. Egan AM, Dennedy MC, Al-Ramli W, et al. ATLANTIC-DIP: excessive gestational weight gain and pregnancy outcomes in women with gestational or pregestational diabetes mellitus. J Clin Endocrinol Metab 2014;99:212-19.

21. Kim SY, Sharma AJ, Sappenfield W, et al. Association of maternal body mass index, excessive weight gain and gestational diabetes mellitus with large-for-gestational-age births. Obstet Gynecol 2014; $123: 737-44$

22. Alberico S, Montico M, Barresi V, et al. The role of gestational diabetes, pre-pregnancy body mass index and gestational weight gain on the risk of newborn macrosomia: results from a prospective multicentre study. BMC Pregnancy Childbirth 2014; $14: 23$

23. Han YS, Ha EH, Park HS, et al. Relationships between pregnancy outcomes, biochemical markers and pre-pregnancy body mass index. Int J Obes 2011;35:570-7.

24. Yu Z, Han S, Zhu J, et al. Pre-pregnancy body mass index in relation to infant birth weight and offspring overweight/obesity: a systematic review and meta-analysis. PIOS ONE 2013;8:e61627.

25. Cogswell ME, Serdula MK, Hungerford DW, et al. Gestational weight-gain among average-weight and overweight women-what is excessive? Am J Obstet Gynecol 1995;172:705-12.

26. Krasovec K, Anderson MA. Maternal nutrition and pregnancy outcomes: anthropometric assessment. PAHO, 1991.

27. Durnin JV. Energy requirements of pregnancy: an integration of the longitudinal data from the five-country study. Lancet 1987;2:1131-3.

28. Hu X, Liu X, Zhang L, et al. Association between pre-pregnancy body mass index and maternal weight gain and birth weight. Chin $J$ Obstet Gynecol Pediatr (electronic version) 2009;5:496-500.

29. Charles RB, Beckmann WH, Laube D, et al. Obstetrics and Gynecology. 7th edn. Lippincott Williams \& Wilkins, 2013.

30. Chen C, Lu FC. The guidelines for prevention and control of overweight and obesity in Chinese adults. Biomed Environ Sci 2004:17(Suppl):1-36.

31. Yaktine AL, Rasmussen KM. Weight gain during pregnancy: reexamining the guidelines. National Academies Press, 2009.

32. Zhang CH, Liu XY, Zhan YW, et al. Effects of prepregnancy body mass index and gestational weight gain on pregnancy outcomes. Asia Pac J Public Health 2015;27:620-30.

33. Nohr EA, Vaeth M, Baker JL, et al. Combined associations of prepregnancy body mass index and gestational weight gain with the outcome of pregnancy. Am J Clin Nutr 2008;87:1750-9.

34. Li N, Liu E, Guo J, et al. Maternal prepregnancy body mass index and gestational weight gain on offspring overweight in early infancy. PloS ONE 2013;8:e77809.

35. Bhattacharya S, Campbell DM, Liston WA. Effect of Body Mass Index on pregnancy outcomes in nulliparous women delivering singleton babies. BMC public health 2007;7:168

36. Di Benedetto A, D'Anna R, Cannata ML, et al. Effects of prepregnancy body mass index and weight gain during pregnancy on perinatal outcome in glucose-tolerant women. Diabetes Metab 2012;38:63-7.

37. Cedergren Ml. Optimal gestational weight gain for body mass index categories. Obstet Gynecol 2007;110:759-64.

38. Cnattingius S, Bergstrom R, Lipworth L, et al. Prepregnancy weight and the risk of adverse pregnancy outcomes. $N$ Engl J Med 1998;338:147-52.

39. Stotland NE, Cheng YW, Hopkins LM, et al. Gestational weight gain and adverse neonatal outcome among term infants. Obstet Gynecol 2006;108:635-43.

40. Hutcheon JA, Platt RW, Meltzer SJ, et al. Is birth weight modified during pregnancy? Using sibling differences to understand the impact of blood glucose, obesity and maternal weight gain in gestational diabetes. Am J Obstet Gynecol 2006;195:488-94.

41. Gluckman PD, Hanson MA. Living with the past: evolution, development and patterns of disease. Science 2004;305:1733-6.

42. Rosenberg TJ, Garbers S, Chavkin W, et al. Prepregnancy weight and adverse perinatal outcomes in an ethnically diverse population. Obstet Gynecol 2003;102:1022-7. 